\title{
Experiment of Multispectral Images using Spectral Angle Mapper Algorithm for Land Cover Classification
}

\author{
KeertiKulkarni, P. A. Vijaya
}

\begin{abstract}
Urbanization plays a key role in the health of the water bodies in any region. In a rapidly growing country like India, especially Bangalore district, rapid urbanization has seen a steep decline in the number of water bodies the region is famous for. In this paper, Land Use and Land Cover change is analysed for the remotely sensed images of Bangalore District using Spectral Angle Mapper Algorithm. Data for the purpose of analysis was obtained from BHUVAN (NRSC, ISRO). The study area is Bangalore District and data was collected from the time period 2008-2016. The major classes used in the classification are Land(Built-up), water bodies (Lakes), Vegetation (Gardens), Soil (Barren and fertile). The satellite images and the accompanying classification algorithms indicate that the percentage of water bodies have drastically shrunk (from $2.9 \%$ in $2008 t o 1.8 \%$ in 2016) in the area of study. The results of this study can be used by the civic authorities to implement decisions to conserve the water bodies in the area.
\end{abstract}

Keywords: Land Use and Land Cover (LULC), Bangalore District, Multispectral Images, Spectral Angle Mapper Algorithm.

\section{INTRODUCTION}

Human activities in an ever growing city like Bangalore have endangered the water bodies in the surrounding regions. More number of buildings and other infrastructure facilities to accommodate the increasing population has resulted in the shrinking of the lakes this city is famous for.Bangalore was known as the 'City of Lakes'. The lakes in the city have been largely encroached for urban infrastructure and as result, in the heart of the city only 17 good lakes have survived as against 51 healthy lakes in 1985.Urban development has caused 19 lakes getting converted to bus stands, Golf courses, playgrounds and residential colonies, and few tanks were breached under the malaria eradication program.. Land Use and Land Cover change refers to the use of the physical characteristics of the surface of the earth. Analysing this Land use and land cover change is very important from the view point of civic administration. Satellite Imagery aides in this kind of an analysis. The study area is Bangalore District which roughly occupies an area of 2196 square kilometres. Base year is 2008. Satellite Imagery is collected from Landsat (USGS) website and also BHUVAN (NRSC, ISRO).

There are two types of remotely sensed images depending on the number of bands of operation. Multispectral images and Hyperspectral images. Multispectral images contain less

Revised Manuscript Received on April 12, 2019.

KeertiKulkarni,Asst. Prof, Dept. Of ECE, BNMIT, Bangalore. (Email:keertikulkarni@bnmit.in)

Dr.P. A. Vijaya,Prof \& Head, Dept. Of ECE, BNMIT, Bangalore (Email: pavmkv@gmail.com) number of bands (four in case of LISS-3 Images), whereas hyperspectral images contain more number of bands. Choosing a proper band combination is one of the key aspects of classification. A number of techniques have been used for the study of LULC. Here the Spectral Angle Mapper Algorithm is used to show how the area has changed over the years with respect to built-up areas and water bodies.

\section{LITERATURE SURVEY}

Many a times just the classification using remotely sense images is not enough. A more accurate analysis is required. The integration of Geographic Information System (GIS) along with remotely sensed images helps in increasing the accuracy of theclassification process [1]. Predicting the change in the usageof and land cover change is possible as shown by the authors [1] by using Markov Chain analysis. Supervised classification method and the Global Land Cover Facility Site (GLCF) have been used together to increase the accuracy of classification [2].More than one remotely sensed data product was used for the accurate classification as shown in[3].This paper uses the Supervised- Maximum Likelihood Estimation in ERDAS Imagine to observe the landcover changes in the Simly Watershed. Landsat 5and SPOT 5 Images were used for the purpose. Degradation of the wildlife sanctuary in Bangladesh was analysed in [4]. Maximum likelihood classification was used on the Landsat TM and Landsat 8 OLI/TIRS images. The impact of LULC on the land surface temperature (LST) was studied by the authors [5]. More is the built-up area more is the temperature of the land surface. Using the Cartography of the given geographic area also helps in increasing the accuracy as shown by the authors [6].This paper presents an integrated approach for LULC Mapping. The authors have used Remote Sensing, GIS and Cartography to map the land cover. The validation of the results was done using the normalized difference indices.[7] This paper presents the use of Supervised Classification methods integrated with the GIS (Geographic Information Systems) in the classification of land use and land cover. A novel scheme of integrating pixel and object based methods with knowledge was used which gives a classification accuracy of around $80 \%$.Ground truth or the field survey is an important part of the validation of the results of classification[9]. In this paper the authors have emphasized the use of field survey along with the 
remotely sensed images in the complete mapping of LULC.Pre-processing of the remotely sensed data plays an important role in the classification process[10] In this paper the authors have presented the use of both pre-processing and post processing techniques to evaluate the landscape changes in the said geographical area. Classification algorithm used is Maximum Likelihood Detection whereas the postprocessing involves the use of Normalized Difference Vegetation Index (NDVI) to map the landscape.

\section{GEOGRAPHICAL AREA OF STUDY}

The study area is the south of Bangalore Urban District with the range $77.5 \mathrm{E}, 13 \mathrm{~N}$ to $77.75 \mathrm{E}, 13 \mathrm{~N}$. Satellite Imagery is collected from BHUVAN (NRSC, ISRO). Two datasets have been used one collected on $12^{\text {th }}$ Nov 2008 and the other on $16^{\text {th }}$ February 2016. Both the datasets have been orthorectified. Bangalore is a city with a population density of 4,381 people per sq. $\mathrm{km}$. whereas in 2001 , it was 2,985 people per sq. $\mathrm{km}$.

\section{METHOD OF ANALYSIS}

\subsection{Datasets used}

Table 1 shows the properties of the data set used. Table 2 shows the different Bands of LISS-3 and their applications

Table 1 : Dataset used

\begin{tabular}{|c|c|c|c|c|c|}
\hline $\begin{array}{c}\text { Data } \\
\text { Set }\end{array}$ & $\begin{array}{c}\text { Year of } \\
\text { Acquisition }\end{array}$ & $\begin{array}{c}\text { Spatial } \\
\text { Resolution }\end{array}$ & Source & Format & $\begin{array}{c}\text { Cloud } \\
\text { Coverage }\end{array}$ \\
\hline 1. & $\begin{array}{c}12^{\text {th }} \mathrm{Nov} \\
2008\end{array}$ & $24 \mathrm{~m}$ & $\begin{array}{c}\text { LISS-3 } \\
\text { Resourc } \\
\text { esat-2 }\end{array}$ & $\begin{array}{c}\text { GeoTiff } \\
\text { (Raster) }\end{array}$ & $10 \%$ \\
\hline 2. & $\begin{array}{c}16^{\text {th }} \mathrm{Feb} \\
2016\end{array}$ & $24 \mathrm{~m}$ & & \\
\hline
\end{tabular}

Table 2 : different Bands of LISS-3 and their uses

\begin{tabular}{|l|l|l|l|}
\hline $\begin{array}{l}\text { Band } \\
\text { number }\end{array}$ & $\begin{array}{l}\text { Wavelength in } \\
\text { micrometer }\end{array}$ & $\begin{array}{l}\text { Spectral } \\
\text { Location }\end{array}$ & Principal Application \\
\hline 1 & $0.45-0.52$ & Blue & $\begin{array}{l}\text { Helps in detection of } \\
\text { water }\end{array}$ \\
\hline 2 & $0.52-0.60$ & Green & $\begin{array}{l}\text { Helps in detection of } \\
\text { green vegetation }\end{array}$ \\
\hline 3 & $0.60-0.69$ & Red & $\begin{array}{l}\text { Helps in analysis of } \\
\text { chlorophyll absorption }\end{array}$ \\
\hline 4 & $0.7-0.90$ & SWIR & $\begin{array}{l}\text { Helps in finding } \\
\text { different vegetation } \\
\text { types }\end{array}$ \\
\hline
\end{tabular}

\subsection{Preprocessing}

Pixel Values are generally defined in terms of Digital Numbers (DN Values).DN values are obtained by the energy reflected by the remotely sensed object which is measured at the sensor. LISS-3 remote sensing sensors measure Radiance, Reflectance, and Top of Atmosphere (TOA) Radiance. Radiance comprises of three components. First, the radiation directly reflected from the surface of the earth, second, the radiation that bounces in from neighboring pixels, and the third, the radiation reflected from clouds. Radiance depends on two factors, the intensity and the direction of illumination. It also depends on the orientation and position of the target. Wavelength dependent scattering causes thelight through the atmosphere to change its path as it travels down to the earth through the atmosphere. Some more scattering takes place when the light travels back to the sensor making its way through the atmosphere. Therefore we need to emphasize the use Top of Atmosphere (TOA) reflectance values instead of DNs.

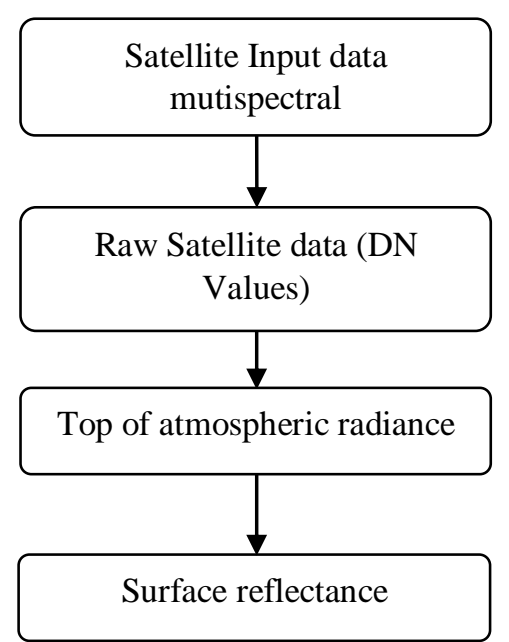

Figure1 : Flowchart for Preprocessing

\subsection{Classification using Machine Learning}

Firstly, training data, also called Region of Interest (ROI) is collected from the remotely sensed images. Care is taken to ensure that the training data comprises of all the possible classes found in the image. Then the spectral angle mapping algorithm is applied to the training data. The output of the algorithm is first validated on a small test area of the image. If the classification is found to be satisfactory then the algorithm is applied to the entire image. Similar procedure is applied to all the datasets under consideration, so that a comparative analysis can be done.

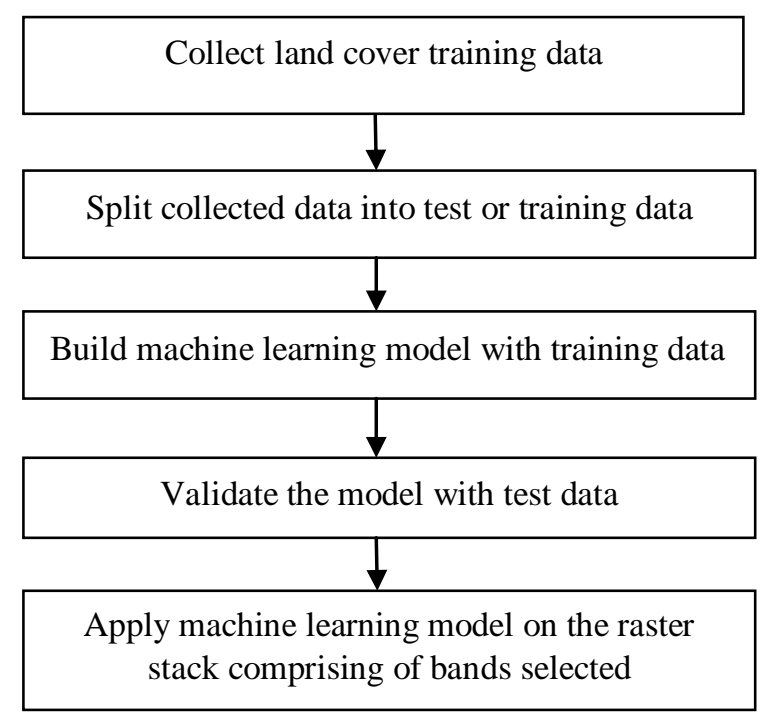

Figure 2 :Workflow for implementing the classification using Machine Learning Algorithms 


\section{Spectral Angle Mapper Algorithm}

The Spectral Angle Mapper Algorithm calculates the spectral angle between spectral signatures of image pixels and training spectral signatures. The spectral angle $\theta(a, b)$ is defined as:

$$
\theta(a, b)=\cos ^{-1}\left\{\frac{\sum_{i=1}^{n} a_{i} b^{i}}{\left(\sum_{i=1}^{n} a\right)^{\frac{1}{2}}\left(\sum_{i=1}^{n} b_{i}^{2}\right)^{\frac{1}{2}}}\right\}
$$

Where:

$\mathrm{a}=$ spectral signature vector of an image pixel;

$\mathrm{b}=$ spectral signature vector of a training area;

$\mathrm{n}=$ number of bands in the remotely sensed image.

Hence, a pixel belongs to the class having the lowest spectral angle.

$$
a \in C_{a} \leftrightarrow \theta\left(a, b_{k}\right)<\theta\left(a, b_{j}\right) \forall k \neq j
$$

Where:

$\mathrm{Ck}=$ land cover belonging to class $\mathrm{k}$; $\mathrm{yk}=$ spectral signature of class $\mathrm{k}$; $\mathrm{yj}=$ spectral signature of class $\mathrm{j}$

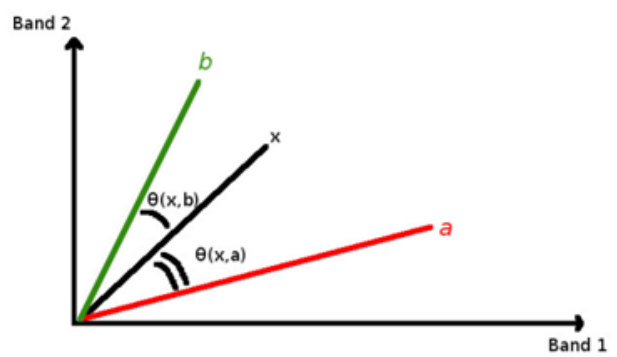

Figure 3 : Spectral Angle for different pixels

\section{RESULTS AND DISCUSSION}

Figure 5.1 shows the study area to which the classification algorithm has been applied. Figure 5.2 and Figure 5.3 show the different band combinations to be used in the classification process against the backdrop of the Bangalore Urban District Map.

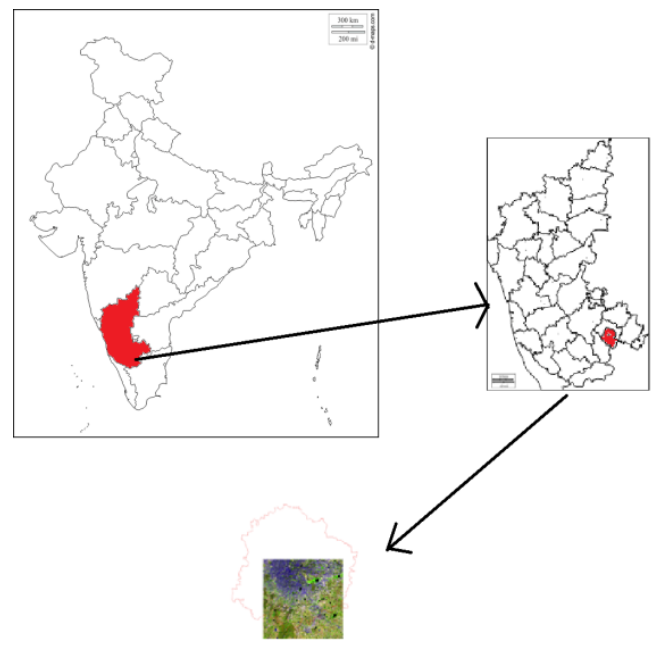

Figure5.1 : Study Area

\section{Results using RESOURCESAT-2 Images:}

Resourcesat 2 LISS-3 Images were downloaded for the purpose of analysis. They have a resolution of $24 \mathrm{~m}$. A different band combination 4-3-2 and 3-2-1 was used to train the pixels. Band combination helps in identifying the different land covers. For example, in band combination 32-1 vegetation shows up in red whereas in band combination 4-3-2 vegetation is green. Hence it is also called as the Natural Colour Composite. Figure 5.4 shows the Land Classification for a remotely sensed image of 2008, whereas Figure 5.5 shows the Land Classification for the remotely sensed image of 2016. A Classification report of both is generated which further helps in plotting the bar chart shown in Figure 5.6.
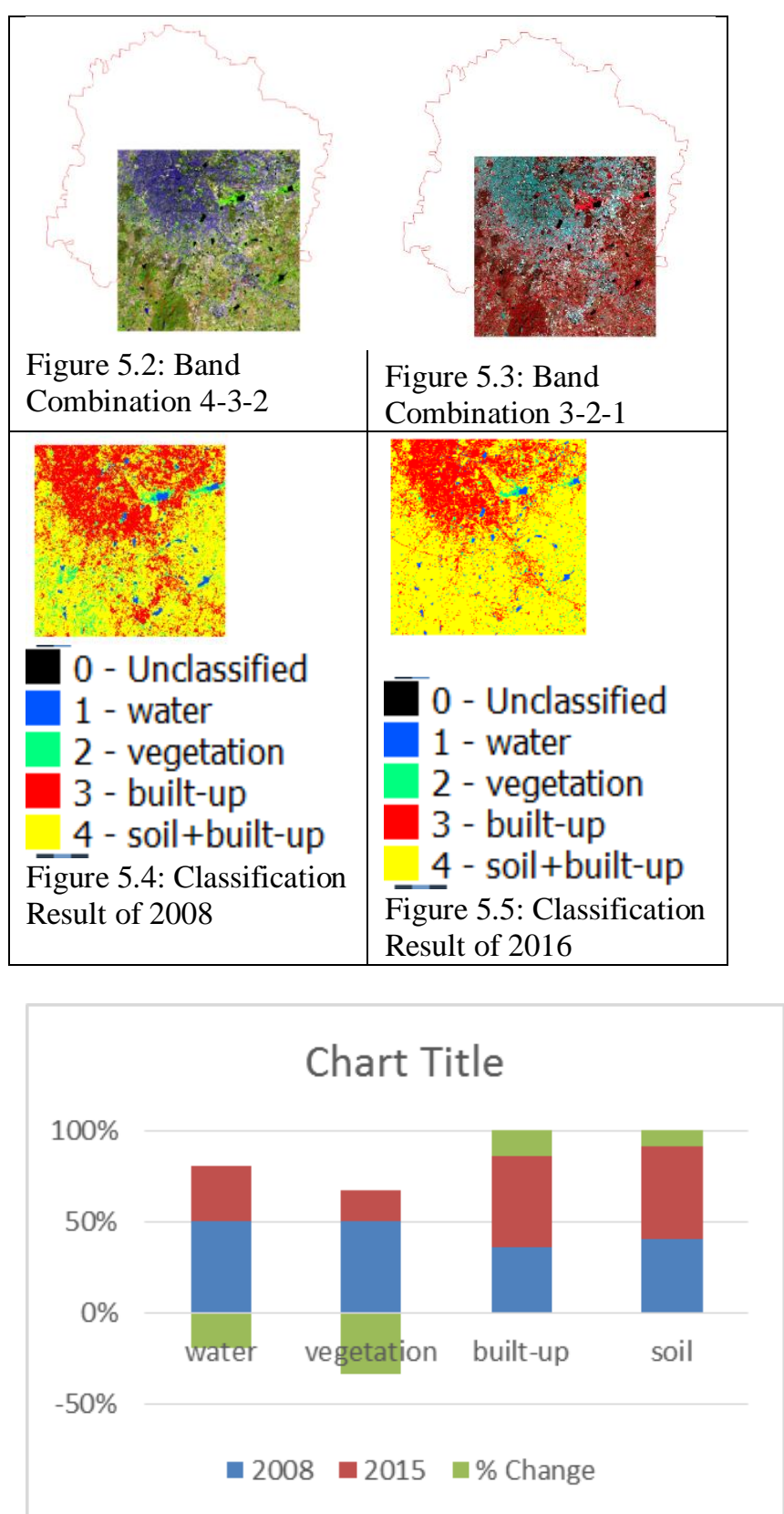

Figure5.6: Land Cover Change 
The bar chart clearly indicates that the rampant urbanization has taken a toll on the natural resources. The increase in the built-up area by nearly $10 \%$ and the decrease in the percentage of water(decrease by $1.1 \%$ ), vegetation (decrease by $4 \%$ ) and barren soil (increase by 13\%) further emphasizes the point.

\section{REFERENCES}

[1] Monitoring urban growth and land use change detection with GIS and remote sensing techniques in Daqahlia governorate Egypt, Ibrahim RizkHegazyaMosbehRashedKaloopb, International Journal of Sustainable Built Environment, Volume 4, Issue 1, June 2015, Pages 117-124

[2] Monitoring land use/cover change using remote sensing and GIS techniques: A case study of Hawalbagh block, district Almora, Uttarakhand, India, J.S.RawataManishKumarb, The Egyptian Journal of Remote Sensing and Space Science, Volume 18, Issue 1, June 2015, Pages 77-84

[3] Land use change mapping and analysis using Remote Sensing and GIS: A case study of Simly watershed, Islamabad, Pakistan,

AmnaButt, RabiaShabbirSheikhSaeedAhmadNeelamAziz, The Egyptian Journal of Remote Sensing and Space Science, Volume 18, Issue 2, December 2015, Pages 251-259

[4] Land use classification and change detection by using multitemporal remotely sensed imagery: The case of Chunati wildlife

sanctuary,Bangladesh,KamrulIslamaMohammedJashimuddina BiswajitNathbTapanKumarNathac, The Egyptian Journal of Remote Sensing and Space Science, Volume 21, Issue 1, April 2018, Pages 37-47

[5] Detection of land use and land cover change and land surface temperature in English Bazar urban centre ,SwadesPalaSk.ZiaulbThe Egyptian Journal of Remote Sensing and Space Science, Volume 20, Issue 1, June 2017 , Pages 125-145

[6] Mapping Land Cover Using Remote Sensing Data and GIS Techniques: A Case Study of PrahovaSubcarpathians, MarinaRamonaRujoiu-MareBogdan-AndreiMihai, Procedia Environmental Sciences, Volume 32, 2016, Pages 244-255

[7] Changes in land use/cover using geospatial techniques: A case study of Ramnagar town area, district Nainital, Uttarakhand, India, J.S.RawataVivekanandBiswasaManishKumarb, The Egyptian Journal of Remote Sensing and Space Science, Volume 16, Issue 1, June 2013, Pages 111-117

[8] Global land cover mapping at $30 \mathrm{~m}$ resolution: A POK-based operational approach,JunChenaJinChenbAnpingLiaoaXinCaobLijunChen aXuehongChenbChaoyingHeaGangHanaShuPengaMiaoLua WeiweiZhangaXiaohuaTongcJonMillsd,ISPRS Journal of Photogrammetry and Remote Sensing, Volume 103, May 2015, Pages 7-27

[9] Land Use-Land Cover dynamics of Hulukawatershed, Central Rift Valley, Ethiopia, HagosGebreslassie1, International Soil and Water Conservation Research, Volume 2, Issue 4, December 2014, Pages 25-33

[10] Land cover change detection using GIS and remote sensing techniques: A spatio-temporal study on TanguarHaor, Sunamganj, Bangladesh, Md. InzamulHaqueRonyBasak, The Egyptian Journal of Remote Sensing and Space Science, Volume 20, Issue 2, December 2017, Pages 251-263

[11] http://bhuvan.nrsc.gov.in

[12] Burgeoning Bangalore City saps its lakes dry

[13] https://www.deccanherald.com/content/25285/vanishinglakes-time-act-now.html

\section{AUTHORS :}

KeertiKulkarni has been working as Assistant Professor in the Department of ECE, B N M Institute of Technology. She has been in the teaching profession since 2000. Currently pursuing her Ph.D degree, her areas of Interest include Satellite Image Processing and Machine Learning.

Dr. P. A. Vijaya, presently Professor and Head of the Department, Department of ECE, B N M Institute of Technology, has over 34 years of teaching Experience. Her areas of Interest include Digital Image Processing, Pattern Recognition and Embedded Systems. She has held several prestigious positions under the VTU. She is also a life member of various technical bodies. 